\title{
Adverse Event Dictionary Derived Term
}

National Cancer Institute

\section{Source}

National Cancer Institute. Adverse Event Dictionary Derived Term. NCI Thesaurus. Code C83344.

An adverse event identifier obtained from a dictionary. 